\title{
Correspondence
}

To the Editors

\section{Antimalarial drug prophylaxis and paediatric COVID-19 in malaria endemic area}

Sri Lanka Journal of Child Health, 2021: 50(2): 365-366

DOI: http://dx.doi.org/10.4038/sljch.v50i2.9594

(Key words: Antimalarial drug prophylaxis, paediatric COVID-19, malarial endemic area)

Dear Editors,

Hydroxychloroquine (HCQ) and chloroquine (CQ) are classic drugs that have been widely used for a very long time. In general, HCQ and CQ are used for malaria treatment and prophylaxis in tropical endemic areas ${ }^{1}$. Additionally, they are used for management of systemic lupus erythematosus and other rheumatological disorders.

In the present COVID-19 crisis, HCQ and CQ have been widely studied for effectiveness in management of the infection. Meo SA, et al suggested the use of HCQ for high risk and outpatient COVID-19 cases $^{2}$. At present, HCQ and CQ are already recommended and used for COVID prevention in some developing countries such as Sudan and India $^{3}$. It is generally recommended for COVID-19 cases who have no co-morbidities and who are immunocompetent ${ }^{4}$. Nevertheless, the lack of data on HCQ and CQ use in healthy people is an important consideration. Indeed, there is an important common use of HCQ and CQ in healthy subjects for malaria chemoprophylaxis. The antimalarial prophylaxis is recommended for any local people, including children, in malarial endemic areas $^{5}$.

Previous studies of efficacy of HCQ and CQ as COVID-19 chemoprophylaxis are mainly from the non-tropical countries where malaria is are $^{6}$. In a recent report from a tropical country, Brazil, the effect of HCQ in COVID-19 was inconclusive? Further studies are required. Here, we would like to discuss the epidemiological record of COVID-19 in Indochina, where malaria is highly endemic. Of interest, the COVID-19 situation in Indochina is not serious when compared to Western countries. Also, the disease is usually not severe. In Myanmar where there are many cases of COVID-19, very few cases occur in the highly endemic malarial areas. In those areas, such as Kayah State, antimalarial prophylaxis is generally used and local children regularly received the prophylactic drugs ${ }^{4}$. There is no report of paediatric COVID-19 in that state. Similarly, in Thailand, Laos and Vietnam, although there are many COVID-19 patients, there are few paediatric cases and there are usually no paediatric cases in the malarial endemic areas. A recent report showed that a COVID-19 paediatric case showed dramatic improvement after HCQ therapy ${ }^{8}$. The report on a simulation study from the Netherlands also supports the use of an adjusted dose of CQ for treatment of paediatric COVID-199. The observation on the real situation of use of HCQ and CQ among healthy children in this area might be a useful clue for further study on the effects of the drugs in the present COVID-19 crisis.

\section{References}

1. Plantone D, Koudriavtseva T. Current and future use of chloroquine and hydroxychloroquine in infectious, immune, neoplastic and neurological diseases: A mini-review. Clinical Drug Investigation 2018; 38(8): 653-71. https://doi.org/10.1007/s40261-018-0656$\mathrm{y}$

PMid: 29737455

2. Meo SA, Klonoff DC, Akram J. Efficacy of chloroquine and hydroxychloroquine in the treatment of COVID-19. European Review for Medical and Pharmacological Sciences 2020; 24(8): 4539-47.

3. Abena PM, Decloedt EH, Bottieau E, Suleman F, Adejumo P, Sam-Agudu NA, et al. Chloroquine and hydroxychloroquine for the prevention or treatment of COVID19 in Africa: Caution for inappropriate offlabel use in healthcare settings. American Journal of Tropical Medicine and Hygiene 2020; 102(6): 1184-8. https://doi.org/10.4269/ajtmh.20-0290 PMid: 32323646 PMCid: PMC7253100

4. Nikpour M, Teh B, Wicks IP, Pellegrini M. Correspondence regarding research letter to the editor by Mathian et al, 'Clinical course of coronavirus disease 2019 (COVID-19) in a series of 17 patients with systemic lupus under long-term treatment with hydroxychloroquine'. Annals of the 
Rheumatic Diseases 2020: annrheumdis2020-217827.

https://doi.org/10.1136/annrheumdis2020-

217827

PMid: 32471898

5. Kramer MH, Lobel HO. Antimalarial chemoprophylaxis in infants and children. Paediatric Drugs 2001; 3(2): 113-21. https://doi.org/10.2165/001280722001030 20-00004

PMid: 11269638

6. Abd-Elsalam S, Elkadeem M, Glal KA. Chloroquine as chemoprophylaxis for COVID-19: Will this work? Infectious Disorders - Drug Targets 2020 Jul 26. https://doi.org/10.2174/187152652066620 0726224802

7. Pillat MM, Krüger A, Guimarães LMF, Lameu C, de Souza EE, Wrenger C, et al. Insights on chloroquine action: Perspectives and implications in malaria and COVID-19. Cytometry Part A 2020; 97(9): $872-81$.

https://doi.org/10.1002/cyto.a.24190

PMid: 32686260 PMCid: PMC7404934
8. Sukhdeo S, Negroponte E, Rajasekhar H, Gaur S, Horton DB, Malhotra A, et al. Acute respiratory distress syndrome and COVID-19 in a child with systemic lupus erythematosus. Lupus 2021; 961203321989791. https://doi.org/10.1177/096120332198979 1

PMid: 33509065

9. Verscheijden LFM, van der Zanden TM, van Bussel LPM, de Hoop-Sommen M, Russel FGM, Johnson TN, et al. Chloroquine dosing recommendations for paediatric COVID-19 supported by modeling and simulation. Clinical Pharmacology and Therapeutics 2020; 108(2): 248-52. https://doi.org/10.1002/cpt.1864 PMid: 32320477 PMCid: PMC7264731

\footnotetext{
*Amnuay Kebayoon ${ }^{1}$, Viroj Wiwanitkit ${ }^{2}$

${ }^{1}$ Private Academic Consultant, Samraong, Cambodia

${ }^{2}$ Adjunct Professor, Joseph Ayobaalola University, Ikeji-Arakeji, Nigeria; Honorary professor, Dr DY Patil University, Pune, India

*Correspondence: amnuaykleebai@gmail.com

iD https://orcid.org/0000-0002-1976-2393

Open Access Article published under the Creative

Commons Attribution CC-BY (c) (i) License
} 